\title{
RESEÑA: CON \& VERSOS. POETAS ANDALUCES PARA EL SIGLO XXI. ANTONIO MORENO AYORA ${ }^{1}$
}

\author{
Juan de Dios Torralbo Caballero²
}

\begin{abstract}
Antonio Moreno Ayora, Con \& versos. Poetas andaluces para el siglo XXI. Sevilla: La Isla de Siltolá, 2014. ISBN: 978-84-16210-008
\end{abstract}

El volumen que la editorial de Sevilla acaba de publicar contiene dieciocho mujeres poetas, alojadas entre las 420 páginas de un libro oportunamente desglosado en cinco bloques de contenido, siendo importante saber que el primero de estos apartados se titula "Criterios de base" por exponer las directrices que su autor ha seguido en la elección de los autores incluidos. Esto implica que el segundo comience tratando "La fructífera década de 1950" para centrarse en los primeros trece poetas estudiados y que en el siguiente titulado "1960, el origen de la postmodernidad" se incluya ya a siete mujeres poetas. Si el cuarto bloque "Apuntando al nuevo siglo: poetas nacidos en 1970" sirve de referencia para otros siete nombres de mujeres escritoras, el último, "La poesía del siglo XXI, plenitud de los años 80", incorpora otros cuatro nombres de mujeres poetas.

Estos datos, puramente objetivos y matemáticos, dan fe de un cierto equilibrio a la hora de precisar la nómina de autores y autoras que componen la antología y el estudio. Antonio Moreno Ayora selecciona, como flores del jardín, dieciocho nombres femeninos y los clasifica por décadas de nacimiento, espigando su temática, su estilo poético y presentando algunos poemas inéditos de cada una de las autoras. Así el crítico cordobés,

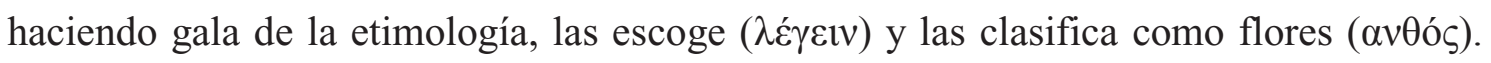

\footnotetext{
${ }^{1}$ Fecha de recepción: 03/06/2014.

Fecha de aceptación: 02/07/2014.

2 Profesor Titular de Universidad, Departamento de Filología Inglesa y Alemana, Universidad de Córdoba, España; $\bowtie 122$ tocaj@uco.es.
} 
Pero el trabajo de este Catedrático de lengua y literatura va más allá porque, como se ha dicho, antepone a cada autora una original nota biográfica de ágil lectura ("Biobliografía") tras la que da cuenta de la "Poética y crítica literaria" (este es el título que escribe) de cada una de ellas.

La primera década que aborda solamente contiene el nombre, el estudio y la obra de escritores hombres que son Juan Cobos Wilkins, Manuel Gahete, Luis García Montero, Carmelo Guillén Acosta, Alejandro López Andrada, José Lupiáñez, Francisco Morales Lomas, Eladio Orta, Francisco Ruiz Noguera, José Antonio Sáez, Fernando Sánchez Mayo, Juan José Téllez y Fernando de Villena. Sin embargo, la década de los sesenta sí incorpora ya a siete mujeres entre los nombres de Álvaro García, Antonio Luis Ginés, Julio César Jiménez, Manuel Moya, Luis Muñoz y Javier Sánchez Menéndez. Siendo la malagueña Isabel Bono la primera, la cual destaca por el elevado número de libros de poesía que ha publicado hasta la fecha así como por su colaboración en revistas especializadas. Cuatro poemas inéditos componen su muestra lírica, de los que el último "La venganza es un cerco de barro" comienza así:

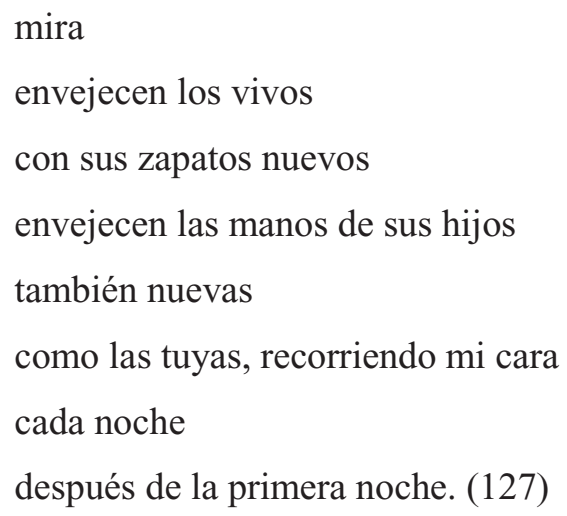

Aurora Luque (Almería) es la segunda, quien además de haber dirigido colecciones de poesía y el Centro Cultural Generación del 27 de Málaga, también hace dos años participó en el programa de escritores europeos en Villa Yourcenar (Flandes). Su labor poética, que queda igualmente enriquecida por la práctica de la traducción literaria -"tarea de creación paralela"-, la ejemplifica Moreno Ayora con seis poemas de los que reproducimos "Museo de Historia Natural" debido a su brevedad: 
Los riachuelos y la microfauna

que dan en llamar cuerpo.

Y luego,

los glaciares, los fósiles:

una gota de ámbar

para guardar un élitro. (154)

Rosario Pérez Cabaña, nacida en Sevilla y profesora en esta Universidad, ofrece dos interesantes vertientes, la investigadora y la creadora, resaltando la primera por sus trabajos sobre lírica hispanoamericana y teniendo en ella a una de las más renombradas estudiosas de la poesía cubana. Cuatro poemas componen la muestra. El primero es "Se oían golpes", inspirado en César Vallejo, que comienza:

Se oían golpes a mi lado.

Un temblor oclusivo y metálico que no llegaba a mi cuerpo

pero estaba ahí, rondando mis costillas. Golpes

como de azada en la tierra pedregosa, $[\ldots](178)$

Charo Prados (Alcalá del Río, Sevilla) es primer premio de poesía de 1983 de la Facultad de Filología de la Universidad de Sevilla, y engrosa su currículo por dedicarse asiduamente a la escritura de relatos y cuentos. Los tres poemas inéditos que se le publican llevan los títulos "Luz milagro", "El suicida" y "Muerte en la tarde", aunque solo registramos el primer párrafo de su "Poética y crítica literaria":

A la poesía, más que buscarla, hay que saber esperarla. Cuando viene, eso sí, procuro que encuentre la puerta abierta de par en par. De día o de noche, y, después, solo después, me atrevo a tocarla.

Es entonces cuando acudo con diligencia al trabajo del verso. Pulo piedras, acorto, alargo, descompongo, combinando formas y acentos. [...] (184) 
Balbina Prior (Villaviciosa, Córdoba) es la siguiente poeta que el lector encuentra en la obra de Moreno Ayora. A su destacada formación en Filología Inglesa y a sus interesantes traducciones de Anna Wickham, Emily Dickinson, Donal Hall o Aphra Behn, se une el hecho de que ella misma esté incluida en numerosas antologías de Córdoba y de fuera de la ciudad. Los poemas de Balbina Prior son tres, y suponen un microcosmos de su sensibilidad lírica y literaria: “A Juan”, "Loa cabal” y otro que no lleva cabecera, que por su brevedad reproducimos íntegro:

En este patio cerrado de la Obsesión, una leve pluma desciende en círculos y presa queda ya en el lodo de su herida. (195)

Inmediatamente después que Prior hallamos a María Rosal (Fernán Núñez, Córdoba), profesora de la Universidad de Córdoba que aúna las facetas de la crítica literaria, del relato breve, del ensayo y de la poesía. Junto a sus cuatro poemas "Como quien va a una fiesta", "Mercancías", "Círculo vicioso" y "Jamón” es muy significativa la aportación que hace sobre su propio estilo, que nos confía plena de sinceridad y en cuyo primer párrafo afirma:

Siempre he escrito, desde niña. Creo que la lectura me llevaba a la escritura y viceversa. He tenido también periodos de grandes silencios que no me crean ningún malestar. Escribo poesía cuando me apetece y escribo ensayo cuando me apetece. Escribir es placer no exento de dolor, provocado por la insatisfacción de lo que se persigue. La poesía para mí es ficción, construcción, artificio, que se alimenta de lo más profundo. Es máscara y velo rasgado, una mirada sobre el mundo, a veces amarga, a veces irónica. Poesía es interrogación. (200)

La década de los setenta, como se ha dicho, continúa estructurada en torno a la semblanza, la poética y la obra de siete mujeres poetas, que alternan sus correspondientes páginas con las de Juan Carlos Abril, José Cabrera Martos, José María Jurado, Francisco Onieva, Alejandro Pedregosa, Joaquín Pérez Azaústre y José Luis Rey. 
Marga Blanco Samos (Granada) es la que abre la década. Ha sido finalista del premio Federico García Lorca de Poesía con su libro de 1997 En un continente cualquiera y es asidua participante en diversas revistas especializadas. Son cuatro los inéditos que la representan configurando su universo lírico y su personal dicción: "Infancia en Tonle Sap", "Un sueño duele", otro que va encabezado con "El amor en su última forma es dejarse morir al lado" de Juan Varo Zafra y otro inspirado en "Y veas lo que nunca has visto” de Juan Antonio Muñoz Rojas. Se reproduce el fragmento sobre su estilo:

Escribir un poema como se pide un deseo. Enfrentarse al folio en blanco como a unas sábanas frías. Dejar el tiempo que haga falta amontonadas las letras con la ropa. Al final las cosas aparecen escritas de otro modo, pero lo fundamental es que uno no salga ileso, que el filo del papel también nos haga daño. (234)

Begoña Callejón (Almería) es la mujer que se incluye de época de los 70. No solo es poeta sino por añadidura narradora - por ejemplo, ha ganado el premio Carmen de Burgos de Almería en 1998- y colaboradora en diversos medios de comunicación y actualmente imparte clases a futuros escritores. "La copa de cristal", "Salí corriendo", "Directamente a la boca" y "La ropa sucia" son las cuatro piezas que Moreno Ayora incorpora en su libro. "La ropa sucia” suena así:

Me seco con una caja de kleneex. Me arrugo. Me bebo un ron cola. No debería. Unos brazos pecosos me envuelven. Estoy fuera de mí. Furiosa con la nieve ¿por qué nieva? Dejadme tocar el tambor, quiero tener quince años y morirme de nuevo, dejadme por favor.

... Y así me convierto en un árbol, en una parte del bosque. (255)

Entre las circunstancias vitales que se anotan de Sara Castelar Lorca (nacida en Hannover y residente en Sevilla) están la de haber recibido varios premios como el del VII Certamen de Poesía de la Fundación de la Mujer de Cádiz (2008) y el de que sus versos hayan aparecido en numerosas revistas de poesía. El poema inédito que aporta a 
la antología es una "Selección de Ved el silencio", y está compuesto por ocho bloques. La introducción a su estilo dice así:

Según José Ángel Valente el poema es un conocimiento haciéndose, y yo estoy de acuerdo con ese planteamiento, porque el poema puede ser un enigma para el propio poeta; sería un fruto que se adentra al árbol, un suceso que irrumpe sin avisarnos y nos hace responsables de su materialización. La palabra que conforma el poema tiene nombres comunes (léxico común) y de fácil asimilación, pero en su anatomía esta materia se vuelve nueva, nunca habitada. [...] (258)

Otra malagueña es María Eloy-García, que también ha visto sus poemas publicados en revistas como Litoral, El Maquinista de la Generación o Nayagua, entre otras. Cuenta con unos siete libros de poesía y sus piezas se pueden leer en antologías diversas. Un ejemplo reciente es Último ahora. Quince poetas (Izana Ediciones, Madrid, 2013). Los poemas inéditos que recoge Antonio Moreno son "Liftin inverso" y "La historiografía de estar siendo", incorporados después de su "Poética y crítica literaria", en la que de manera gráfica declara:

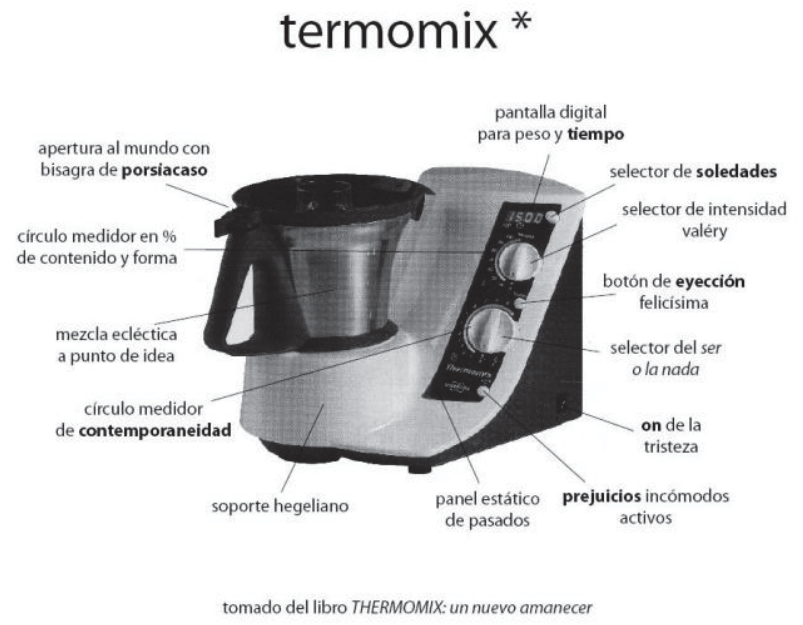

Vid. Con \& Versos. Poetas andaluces para el siglo XXI, 2014: 266 
Y sevillana es Rocío Hernández Triano, mujer creadora y docente de lengua y literatura, lo que además ha confirmado mediante la publicación de varios libros de texto. Como poeta ha editado tres libros de poesía, dos en 2010 y otro en 2013 que le ha supuesto conseguir el XXX Premio de Poesía Carmen Conde. Su obra, también inserta en revistas literarias, puede leerse igualmente en algunas antologías líricas. En esta antología se transcriben sus tres poemas son "Mi grito en el cielo", "Ensayo sobre terrores" y "Clase media". Este último comienza y termina así:

En mil novecientos noventa todos nuestros padres estaban vivos.

Eran plomo redondo.

Quemaban como luz de fundición

y olían a pelliza de mentira.

Leían el periódico,

confiaban en un futuro inmenso.

La prosperidad era una serpentina que usaban de conjuro. [...]

Recogimos sus restos.

Resultaron ser nada.

Y por ahora somos los molestos tumores de la patria. (278-279)

Raquel Lanseros (Jerez de la Frontera) es la sexta poeta de estos años 70 que el Profesor Moreno Ayora incorpora en el volumen. Destaca por su labor como poeta y como poeta traductora. De hecho, ha conseguido premios como el Unicaja de Poesía, Antonio Machado en Baeza y el de Poesía de Jaén. Su obra se concentra en media decena de libros publicados todos ellos en editoriales de Madrid, y está presente, asimismo, en antologías de Murcia, Logroño y Granada. Precisamente en la ciudad de La Alhambra ha publicado también sus traducciones de Edgar Allan Poe (Poemas de amor, 2013). Las cuatro piezas inéditas que el lector puede disfrutar en Con \& versos son "Tú", "Sigue doliendo España", "Escena de senectud" y "Enlazados", del que traemos la primera estrofa: 


\author{
Existe un modo de felicidad \\ gutural y arbolada, involuntaria \\ que nos colma por dentro como un sueño. \\ Es un torrente limpio, poderoso, \\ un látigo de luz casi intuitivo, \\ la dicha porque sí, \\ por el sencillo don del testimonio. (296)
}

Eva Vaz (Huelva) cuenta con cinco libros de poemas publicados en 2001, 2003, 2004, 2006 y 2012. Con una obra que puede leerse en varias antologías, colabora como columnista en diversos medios de prensa escrita y participa en cursos de animación a la lectura. Junto a Eladio Orta, Antonio Orihuela y Jorge Riechmann, su obra se conceptualiza como "Poesía de la Consciencia". Los poemas inéditos que Antonio Moreno Ayora le incluye en su libro son "Ruido de venenos" y "Sexo, mentiras y Facebook". Ella explica su estilo poético de esta manera:

Mi poesía es una confesión estética, una confesión impúdica y sincera que invita al lector a compartir mis obsesiones y convertirlas en emociones colectivas. En ese viaje, regreso a mí, aliviada y limpia. Esta dialéctica emocional cicatriza el esternón de esta loba tierna. Dicho esto, he de reconocer que la poesía es pura psicoterapia [...]. (342)

La última década que estudia el crítico literario cordobés, que tiñe de continua actualidad su imprescindible antología, es "La poesía del siglo XXI, plenitud de los años 80 ", en donde da fe de la contemporaneidad, de la frescura y de la vigencia absoluta de su trabajo. Solo un experto tan bien avezado y tan bien cultivado en las nuevas corrientes literarias, conocedor tanto de lo clásico como de la última palabra en poesía, puede pergeñar una obra tan de nuestros días como la que aquí se está reseñando. Moreno Ayora destaca como colaborador asiduo de revistas literarias y renombrados periódicos donde reluce esta vertiente de estudioso de la materia literaria y de la obra de arte verbal. Por esto en este segmento, el lector interesado encontrará los nombres femeninos de Nieves 
Chillón, Patricia García-Rojo, Elena Medel y María Ramos; junto a Álvaro García, Antonio Luis Ginés, Julio César Jiménez, Manuel Moya, Luis Muñoz y Javier Sánchez Menéndez.

Nieves Chillón Gázquez (Orce, Granada) es la escritora que inaugura el grupo femenino en este apartado de los 80 . Los primeros frutos poéticos que ven la luz están en la plaquette La hora violeta, publicada por el Ayuntamiento de Granada en 2004. Dos años después, según los datos de Moreno Ayora, publica Morning Blues. Con La canción de Penélope logra el XIX Premio de Poesía Mujerarte (Ayuntamiento de Lucena, Córdoba) en 2011. Al año siguiente consigue el I Premio de Poesía Jorge Manrique y Vinos de Uclés (Vitruvio, Madrid). También recoge el Dr. Moreno Ayora que la escritora se inspira "en la conjunción de lo emocional y lo íntimo con elementos cotidianos, industriales, mecánicos e incluso sucios de nuestro día a día” (Moreno 2014: 356). Las cuatro muestras inéditas que el lector encontrará son "Rosa blanca", "Niebla", "Máquina de refrescos" e "Incandescencia". "Rosa blanca" consta de estos seis versos:

\footnotetext{
En la amarilla agonía de la luna las hélices rotas del corazón se deshojan, se desprende un diente de leche, caen al suelo las almas de los perros como pétalos marfil de una rosa a la que no daré más tinta. (358)
}

Patricia García-Rojo (Jaén) es la segunda poeta nacida en la década de los ochenta que recoge el ensayista cordobés. En 2007 merece el premio Andalucía Joven de Narrativa del Instituto Andaluz de la Juventud -el cual le permite publicar su novela titulada La Fábrica Creátor (Los portales de Éldonon I), hacia 2010 declama sus versos en el bar La Botica de Málaga, y su primer poemario sale de las prensas en 2012 (Amar es aquí), momento a partir del cual sus poemas se encuentran en diversas antologías. Los títulos de los aportados para este libro, todos en minúscula, son "por si debes definirte y 
no te encuentras", "y entonces dios unió a las mujeres con recetas", "yo nunca sé" y "ahora", que reproducimos completo:

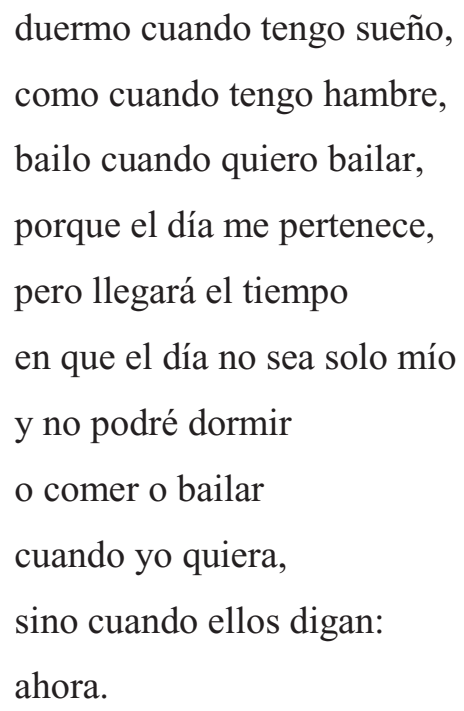

Elena Medel (Córdoba) es la siguiente poeta de este bloque, nacida en el ecuador de la década. Su primer libro de poesía data de 2002 (Mi primer bikini), cuatro años después publica Tara y este mismo año ha logrado el XXVI Premio Loewe a la Creación Joven con Chaterton. Sus versos pueden leerse tanto en español en diversas antologías como en otro idiomas. Por Antonio Moreno Ayora sabemos que ha participado con columnas de opinión en prensa escrita de carácter local, regional y nacional y que está al cuidado de la editorial La Bella Varsovia junto a la también escritora Alejandra Vanessa. El primer poema inédito que recoge el libro lleva como cabecera "Estamos realizando obras en el exterior. No utilizar esta puerta excepto en caso de emergencia". La segunda composición se titula "A Virginia, madre de dos hijos, compañera de Primaria de la autora". La anotación sobre "Poética y crítica literaria" es bastante significativa y comienza así:

¿Árbol genealógico? Recuerdo una frase de Txomin Badiola: "arreglárselas no solo sin el padre, sino sin la posición que dejó vacante". Es decir: aun desde la consciencia de escribir tras la obra de determinados autores, y bajo su influencia -doten a las 
preposiciones de la importancia que merecen, apostar por la búsqueda de una voz diferente, nueva, sin ecos, que ocupe ese espacio vacio.

Es María Ramos (Almería) no la que cierra el libro sino la que concluye esta dilatada nómina de mujeres poetas. Tiene publicadas varias plaquettes como Vomit your love (2010), Affaire (2011) y Fábulas (2012), pudiéndose leer sus poemas en diversas antologías de 2012 y 2013. Como traductora, destaca su trabajo de Sylvia Plath editado por Nórdica Libros (2013) bajo el título de Tres mujeres, pero lo cierto es que tal labor abarca a Kendra Grant Malone, Ellen Kennedy, Mira González o Dorothea Lasky. La autora asevera: "No pienso en términos poéticos. No pienso en la poesía de forma aislada. Pienso en la creación. En extraer algo de la oscuridad a través de un acto desinteresado de amor" (Moreno 2014: 386). Los inéditos que incorpora son tres (así, "I", "II" y “III"), de los que el primero es:

\section{Vamos -te dije-}

No finjas.

Sabes que será tan fácil

Como un grito.

Tu cuerpo sabrá abrirse camino

Más allá de mi ausencia.

Mi corazón como tierra seca

No es más que eso. (387)

Invitamos al lector interesado a que se sumerja, pues de una placentera e inolvidable inmersión se trata, en la obra y aprenda de la mano del estudio del profesor Moreno Ayora, abriendo el apetito lírico con el apartado sobre la retórica de cada autora que encabeza el espacio y deteniéndose en cada uno de los poemas incluidos, todos inéditos hasta el momento en que se publica la obra.

El Catedrático autor del libro Con \& versos. Poetas andaluces para el siglo XXI predice en su pórtico que el trabajo "puede ser el punto de arranque para posteriores investigaciones o estudios sobre el trascurrir del género lírico a finales del XX y 
comienzos del XXI" (10). Sin duda es lo que puede deducirse y necesariamente esperarse tras haber leído con atención su ingente y holística labor.

Antonio Moreno Ayora es consciente del afán inclusivo y totalizador que tiene su trabajo, pues él mismo dice en el prólogo que "Si alguno de los nombres, del ámbito femenino o masculino", se echa en falta, se deberá posiblemente a esa intención de esencialidad que en todo momento nos ha guiado [...]" (10). Una de las explicaciones de la selección radica en que esté basada, entre otras, en que "la condición de inédito en el momento de aportarnos sus datos era requisito imprescindible para que pudiéramos incluir al poeta en cuestión" (11), y esta exclusividad es la que queremos destacar.

Escribe el antólogo que Con \& versos. Poetas andaluces para el siglo XXI “pretende proporcionar un prontuario de consulta de los principales o más significativos poetas que han publicado en los quince o veinte últimos años del siglo XX y en los primeros lustros del XXI" (11). A la luz de cuanto se recoge en esta reseña, se infiere que lo ha logrado con creces. Llama la atención sobre los autores más jóvenes, cuando dice que "hay que prestar, por tanto, atención a estos nuevos nombres [...] y seguir de cerca su evolución, con la esperanza de que sus impulsos líricos iniciales se consoliden y sigan aportando frescura, originalidad y futuro a la poesía del siglo XXI a la que por derecho ya pertenecen y en cuyo seno representan el obligado relevo generacional de posturas líricas anteriores" (11-12).

A Moreno Ayora le parece conveniente que su antología sea juzgada como “necesaria, esquemática, esencial, manejable y ágil”. Se colige que lo consigue, además de constatarse que ya el libro en sí es un extenso manual de consulta cuya utilidad proviene -como él mismo escribe- "de la considerable información que suministra” (12). No podemos más que felicitarnos y dar la enhorabuena a este constante, renombrado crítico literario andaluz cuyas continuas aportaciones ofrecen una muestra de sus inquietudes culturales y de su constancia como profesor y estudioso. Su prestigio como filólogo y lingüista - no olvidemos que su nombre era uno de los incluidos en la Bibliografía fundamental de la Lengua Española (Castalia, 2000)- y como ensayista y crítico de calidad más que demostrada no es aparición fugaz, sino constante trayectoria a 
la que remiten títulos, entre otros, como La negación en español. Sintaxis y semántica de la incidencia no verbal (2002), La poesía de Ortega Parra (Un viaje invertido) (2005), o Manuel Gahete. El esteticismo en la literatura española (2013), este último el primer estudio sobre la obra de conjunto del mencionado escritor cordobés y publicado por cierto por La Isla de Siltolá igual que esta magna antología de 2014 que estamos seguros que va a tener una larga cola de lectores y de seguidores por muchos años. 